\title{
Acidophilic actinomycetes from rhizosphere soil: diversity and properties beneficial to plants
}

\begin{abstract}
Nalin Poomthongdee ${ }^{1}$, Kannika Duangmal ${ }^{1,2}$ and Wasu Pathom-aree ${ }^{3}$
Three hundred and fifty-one isolates of actinomycetes were recovered from 21 rhizospheric soil samples using acidified media of $\mathrm{pH}$ 5.5. They were evaluated for their antifungal, siderophore production and phosphate solubilization activities. The total count of actinomycetes growing on acidified starch casein agar and Gause no. 1 agar were below $2.48 \times 10^{4} \mathrm{CFU} \mathrm{g}^{-1}$ soil. Two hundred and twelve isolates were assigned to acidophiles and the remaining 139 isolates were neutrophiles. Of these actinomycetes, 57.8, 32.5 and $50.4 \%$, showed antagonistic activity against three rice pathogenic fungi; Fusarium moniliforme, Helminthosporium oryzae and Rhizoctonia solani, respectively. More than half of the isolates $(68.1 \%)$ inhibited at least one tested pathogenic fungus, whereas $\mathbf{2 5 . 9 \%}$ exhibited antifungal activities against all tested fungi. Three hundred and thirty-eight isolates $(96.3 \%)$ produced siderophore and 266 isolates $(75.8 \%)$ solubilized phosphate. A greater proportion of the acidophilic actinomycetes exhibited antifungal, siderophore production and phosphate solubilization activity compared with the neutrophiles. Three hundred and twenty-five isolates (92.6\%) were classified as streptomycetes based on their morphological characteristics and the presence of the $L L$-isomeric form of diaminopimelic acid in whole-cell hydrolysates. The $16 \mathrm{~S}$ ribosomal RNA (rRNA) gene analysis of representative non-streptomycete strains showed that the isolates belonged to seven genera, that is, Allokutzneria, Amycolatopsis, Mycobacterium, Nocardia, Nonomuraea, Saccharopolyspora and Verrucosispora. The potential antifungal acidophilic isolates, R9-4, R14-1, R14-5 and R20-5, showed close similarity to Streptomyces misionensis NBRC $13063^{\top}$ (AB184285) in terms of morphological characteristics and 16S rRNA gene sequences.
\end{abstract}

The Journal of Antibiotics (2015) 68, 106-114; doi:10.1038/ja.2014.117; published online 27 August 2014

\section{INTRODUCTION}

Actinomycetes are a diverse group of Gram-positive bacteria with high GC content, which are common in soil and widely distributed in various environments. They represent the most economically and biologically valuable bacteria among prokaryote, producing various biologically active substances such as antibiotics, antitumors and enzymes. ${ }^{1-3}$ Although actinomycetes are commonly known as neutrophiles, which grow well in neutral or slightly alkaline conditions, a few actinomycetes such as Streptomyces acidiphilus ${ }^{4}$ and members of the genus Streptacidiphilus ${ }^{5}$ have been reported to require acidic conditions ( $\mathrm{pH}$ 2.6-5.5) for growth. In addition, the members of the genera Actinospica ${ }^{6}$ and Catenulispora ${ }^{7}$ are also known as acidophilic actinomycetes.

Acidophilic actinomycetes can be divided into two main groups, which are neutrotolerant acidophiles and strict acidophiles. Typical neutrotolerant acidophiles grow in media at $\mathrm{pH}$ 4.5-7.5 with optimum growth between $\mathrm{pH} 5.0$ and 5.5. Members of strictly acidophilic group typically grow in media between $\mathrm{pH} 3.5$ and 6.5, with an optimum growth at $\mathrm{pH} 4.5 .^{8.9}$ In acidic habitats, the actinomycetes commonly found belong to the genus Streptomyces. ${ }^{10}$

Rice is a staple crop that supports about half of the world's population. However, fungal rice diseases are major problems in rice cultivation. ${ }^{11}$ The use of chemical synthetic compounds is regarded as an effective method for prevention and therapy, but has deleterious effects on health and the environment. ${ }^{12,13}$ It is necessary to find an environmental-friendly alternative for sustainable protection management. Actinomycetes have been considered as potential biocontrol agents against various phytopathogenic fungi because of their production of bioactive metabolites ${ }^{14-16}$ or of enzymes that hydrolyzed fungal cell walls. ${ }^{17-20}$ Most of the previous works were focused on the ability of actinomycetes isolated from neutral $\mathrm{pH}$ isolation media. However, acidophilic actinomycetes were reported to inhibit fungi better than neutrophilic actinomycetes under acidic condition. $^{21}$ Crawford et al. ${ }^{22}$ also reported that acidophilic actinomycetes exhibited strong antagonism toward multiple fungal root pathogens. In addition, Basilio et al. ${ }^{14}$ demonstrated that actinomycetes isolated under alternative selective $\mathrm{pH}$ conditions possess a significant capacity to produce compounds with antimicrobial activity. In rice field soil, the $\mathrm{pH}$ is usually slightly acidic, which is favorable for the growth of pathogenic fungi. The use of acidophilic actinomycetes in the rice field would be more effective than neutrophilic strains. However, little attention has been given to determining the diversity and antifungal activity of acidophilic actinomycetes. Therefore, in this study, actinomycetes were isolated

${ }^{1}$ Department of Microbiology, Faculty of Science, Kasetsart University, Bangkok, Thailand; ${ }^{2}$ Center for Advanced Studies in Tropical Natural Resources, NRU-KU, Kasetsart University, Bangkok, Thailand and ${ }^{3}$ Department of Biology, Faculty of Science, Chiang Mai University, Chiang Mai, Thailand 
from rhizospheric soils under acidic selective conditions and their ability to inhibit the rice pathogenic fungi Fusarium moniliforme, $H$. oryzae and $R$. solani was assessed. The diversity of the actinomycetes obtained was also investigated.

\section{MATERIALS AND METHODS}

Sample collection and selective isolation of actinomycetes

Rhizospheric soil samples (17 samples from rice plants and 4 samples from rubber trees) were collected from several provinces of Thailand (Chiang Mai, Nakhon Sawan, Pathum Thani, Phatthalung, Phetchaburi, Phra Nakhon Si Ayuttaya, Ratchaburi and Suphan Buri). The samples were air dried, and sieved to remove unwanted particles. The $\mathrm{pH}$ of soil was determined according to Davet. ${ }^{23}$ Air dried soil sample was mixed with distilled water at a ratio of 1:2.5, thoroughly mixed and left to stand for $30 \mathrm{~min}$ before $\mathrm{pH}$ measurement with $\mathrm{pH}$ meter. The isolation of actinomycetes was conducted using a dilution plate technique. One gram soil sample was diluted in $4 \mathrm{ml}$ of $0.85 \%(\mathrm{w} / \mathrm{v}) \mathrm{NaCl}$ solution, mixed well and then heat treated at $55^{\circ} \mathrm{C}$ for $10 \mathrm{~min}$ in a water bath to eliminate fast growing bacteria. Serial 10-fold dilutions were prepared for each pretreated sample and aliquots $(0.1 \mathrm{ml})$ of each dilution were spread onto acidified starch casein agar (SCA) ${ }^{24}$ and acidified Gause no. $1,{ }^{25} \mathrm{pH} 5.5$, supplemented with nalidixic acid, nystatin and ketoconazole at final concentration of $25 \mu \mathrm{g} \mathrm{ml}^{-1}, 50 \mu \mathrm{g} \mathrm{ml}^{-1}$ and $100 \mu \mathrm{g} \mathrm{ml}^{-1}$, respectively. Media of pH 5.5 was prepared by mixing sterile double strength media with an equal volume of sterile citrate/phosphate buffer of pH 5.5 ( $0.1 \mathrm{M}$ citrate/ $0.2 \mathrm{M} \mathrm{Na}_{2} \mathrm{HPO}_{4}$ ). The method for $\mathrm{pH}$ adjustment using buffer was applied to all media used in this experiment, otherwise indicated. The plates were incubated at $28{ }^{\circ} \mathrm{C}$ for 28 days, and then the number of actinomycete colonies, recognized by their morphological characteristics, was counted. The colonies were then selected and restreaked on acidified International Streptomyces Project (ISP) medium $2^{26}$ (pH 5.5) for purity checking and maintained on the same medium at room temperature. Spores and mycelial suspensions were stored in $20 \%(\mathrm{v} / \mathrm{v})$ glycerol solution at $-20^{\circ} \mathrm{C}$ as stock culture.

\section{Actinomycete characterization}

Putative actinomycete isolates were characterized by their morphological, chemical and physiological characteristics. Their morphological characteristics were observed on acidified ISP medium $3^{26}(\mathrm{pH} 5.5)$, after incubation at $28^{\circ} \mathrm{C}$ for 14 days. The color of spore mass and diffusible pigment production were determined and recorded by comparison with a color chart. ${ }^{27}$ The isomeric form of 2,6-diaminopimelic acid (DAP) of whole organism hydrolysates was determined using paper chromatography according to the method as described by Hasegawa et al..$^{28}$ and Becker et al. ${ }^{29}$

The assignment of actinomycetes as acidophilic or neutrophilic strains was based on their ability to grow on ISP medium 2 at $\mathrm{pH} 4.5$ and 7.5. The growth of each isolate was observed after being incubated at $28^{\circ} \mathrm{C}$ for 3,7 and 14 days. The isolates that grew better or grew only on acidified media were regarded as acidophiles and the isolates that grew better or grew only on media of $\mathrm{pH} 7.5$ were regarded as neutrophiles. ${ }^{30}$

\section{In vitro antifungal activity}

Antagonistic activity of the isolates against three rice pathogenic fungi F. moniliforme (bakanae), H. oryzae (brown spot) and R. solani (sheath blight), were evaluated on potato dextrose agar (PDA, $\mathrm{pH}$ 5.5) using a dual culture technique. ${ }^{31}$ These fungi were maintained on PDA at room temperature. Two 7-day-old actinomycete discs $(5 \mathrm{~mm})$ grown on acidified ISP medium $2(\mathrm{pH}$ 5.5) were placed on opposite sides, $3 \mathrm{~cm}$ away from the center of the PDA plate. After incubation at $28^{\circ} \mathrm{C}$ for 7 days, a fungal mycelia disc $(5 \mathrm{~mm}$ in diameter) was placed in the center of the plate. PDA plates with fungal mycelia discs in the center of the plate (without actinomycete) served as control. The plates were incubated at $28^{\circ} \mathrm{C}$ until the fungal mycelium of control reached the edge of the plate. The percentage of inhibition was calculated as $[(r 1-r 2) /$ $r 1] \times 100$. Where, $r 1$ is the radial mycelia growth in control and $r 2$ is the radial mycelia growth that occurs toward the actinomycetes. ${ }^{32}$ The experiment was conducted in duplicate.

\section{Screening for siderophore production}

Discs $(5 \mathrm{~mm})$ containing good lawns of actinomycete isolates grown on ISP medium 2 (pH 5.5) at $28^{\circ} \mathrm{C}$ for 7 days were placed on chrome azurol $\mathrm{S}$ agar. ${ }^{33}$ Sterile ISP medium 2 ( $\mathrm{pH}$ 5.5) discs were also placed on chrome azurol S agar as controls. The inoculation plates were incubated at $28^{\circ} \mathrm{C}$ for 5 days. An orange halo around the agar discs was considered as siderophore-producing activity and the diameter of the halo was recorded. The experiment was conducted in duplicate.

\section{Screening for phosphate-solubilizing actinomycetes}

All actinomycete isolates were cultured on ISP medium 2, at pH 5.5 and incubated at $28{ }^{\circ} \mathrm{C}$ for 7 days. Discs $(5 \mathrm{~mm})$ containing good lawn of the isolates were placed on Pikovskaya agar. ${ }^{34}$ The inoculation plates were incubated in the dark at $28^{\circ} \mathrm{C}$ for 14 days. The presence of a clear zone around the agar discs was considered as phosphate-solubilizing activity and the diameter of clear zone was measured. The experiment was conducted in duplicate.

\section{DNA extraction, PCR amplification and sequencing of $16 \mathrm{~S}$} ribosomal RNA (rRNA) gene

Genomic DNA was extracted as described by Kieser et al. ${ }^{35}$ PCR amplification of $16 \mathrm{~S}$ rRNA gene was carried out using the primers: STR1F $\left(5^{\prime}\right.$-TC ACGGAGAGTTTGATCCTG- $\left.3^{\prime}\right)$ and STR1530R (5'-AAGGAGATCCAGCC GCA- $\left.3^{\prime}\right) .{ }^{36}$ The PCR consisted of an initial denaturation step at $94^{\circ} \mathrm{C}$ for $4 \mathrm{~min}$, followed by 30 cycles of $94^{\circ} \mathrm{C}$ for $1 \mathrm{~min}, 57^{\circ} \mathrm{C}$ for $1 \mathrm{~min}, 72{ }^{\circ} \mathrm{C}$ for $1 \mathrm{~min}$ and a final extension step for $10 \mathrm{~min}$ at $72^{\circ} \mathrm{C}$. Sequencing of $16 \mathrm{~S} \mathrm{rDNA}$ was performed using the service of Macrogen (Seoul, Korea) and 1st BASE Laboratory (Selangor, Malaysia), with the same primers as those used for PCR amplification. The resultant sequences were compared with other sequences of related type strains available in the EzTaxon-e database (http://eztaxone.ezbiocloud.net/). The 16S rDNA sequences were aligned with related

Table 1 Soil $\mathrm{pH}$ values, total actinomycete count (CFU per $\mathrm{g}^{-1}$ dry soil) and total number of actinomycete isolated from each soil sample

\begin{tabular}{lccc}
\hline & $\begin{array}{c}\text { Soil } \\
\text { Samples }\end{array}$ & $\begin{array}{c}\text { Total actinomycetes count }\left(\mathrm{CFUg}^{-1}\right) \text { on SCA } \\
\text { medium }\end{array}$ & $\begin{array}{c}\text { Total } \\
\text { isolates }\end{array}$ \\
\hline R1 & 5.3 & $1.36 \times 10^{4}$ & 11 \\
R2 & 5.1 & $2.48 \times 10^{4}$ & 25 \\
R3 & 7.1 & $<30^{\mathrm{a}}$ & 9 \\
R4 & 6.0 & $<30^{\mathrm{a}}$ & 8 \\
R5 & 5.5 & $5 \times 10^{3}$ & 25 \\
R6 & 7.3 & $4.78 \times 10^{3}$ & 14 \\
R7 & 7.6 & $<30^{\mathrm{a}}$ & 16 \\
R8 & 7.2 & $<30^{\mathrm{a}}$ & 27 \\
R9 & 5.4 & $<30^{\mathrm{a}}$ & 20 \\
R10 & 3.1 & $<30^{\mathrm{a}}$ & 3 \\
R11 & 7.0 & $<30^{\mathrm{a}}$ & 28 \\
R12 & 6.7 & $<30^{\mathrm{a}}$ & 1 \\
R13 & 6.6 & $7.02 \times 10^{3}$ & 21 \\
R14 & 7.0 & $7.18 \times 10^{3}$ & 15 \\
R15 & 5.6 & $6.32 \times 10^{3}$ & 21 \\
R16 & 5.1 & $<30^{\mathrm{a}}$ & 23 \\
R17 & 4.7 & $<30^{\mathrm{a}}$ & 9 \\
R18 & 4.7 & $<30^{\mathrm{a}}$ & 24 \\
R19 & 4.7 & $<30^{\mathrm{a}}$ & 10 \\
R20 & 4.8 & $<30^{\mathrm{a}}$ & 16 \\
R21 & 6.5 & $<30^{\mathrm{a}}$ & 25 \\
& & & 351 \\
& & &
\end{tabular}

Abbreviation: SCA, starch casein agar.

actinomycetes number lower than $30 \mathrm{CFU} /$ plate after spread the plate with soil suspension at a dilution of 1:4 and incubated for 4 weeks. 
species using CLUSTALW program. ${ }^{37}$ A neighbor-joining ${ }^{38}$ phylogenetic tree was generated using MEGA version 5.0 software, ${ }^{39}$ evaluated by bootstrap analysis of 1000 replications; a distance matrix was generated using Kimura's 2parameter model. ${ }^{40}$

\section{RESULTS AND DISCUSSION}

\section{Selective isolation of actinomycetes}

Both rice plants and rubber trees can grow in acid soil and the characteristic acidic $\mathrm{pH}$ of paddy soils and of rubber tree plantation soils have been reported. ${ }^{41,42}$ In this study, the $\mathrm{pH}$ of rice rhizosphere soils ( $\mathrm{R} 1$ to $\mathrm{R} 17)$ ranged from strongly acidic to slightly alkaline ( $\mathrm{pH}$ 3.1-7.6) and the rubber tree rhizosphere soils (R18 to R21) were highly acidic to slightly acidic ( $\mathrm{pH} 4.7-6.5$ ) (Table 1 ).

In a preliminary test, five soil samples were used to isolate acidophilic actinomycetes at $\mathrm{pH} 4.5$. One gram of each soil sample was suspended in $4 \mathrm{ml}$ of $0.85 \% \mathrm{NaCl}$, heated at $55^{\circ} \mathrm{C}$ for $10 \mathrm{~min}$ before being spread on acidified SCA medium with $\mathrm{pH}$ adjusted to 4.5 , supplemented with nalidixic acid $\left(25 \mu \mathrm{g} \mathrm{ml}^{-1}\right)$ and nystatin $\left(50 \mu \mathrm{g} \mathrm{ml}^{-1}\right)$. However, after a few days of incubation, most isolation plates were covered with fungal mycelium, which overgrew the small colonies of actinomycetes. As Muramatsu et al. ${ }^{43}$ observed, the isolation of acidophilic actinomycetes is difficult due to fungal contamination, which grow well under acidic conditions. In addition, most antifungal agents such as nystatin are unstable at low $\mathrm{pH}$. Therefore, the isolation media used were evaluated with those soil samples to selectively isolate acidophilic actinomycetes by adjusting the $\mathrm{pH}$ of the media within the range of 4.0-6.0 and supplemented with fungal inhibitors such as salt (sodium chloride and sodium propionate), dyes (rose Bengal and Congo red) and antibiotics (nalidixic acid, nystatin and ketoconazole). The results showed that acidified SCA and Gause no. 1 agar plates of $\mathrm{pH} 5.5$, supplemented with $25 \mu \mathrm{g} \mathrm{ml}^{-1}$ antibiotic nalidixic acid , $50 \mu \mathrm{g} \mathrm{ml}^{-1}$ nystatin and $100 \mu \mathrm{g} \mathrm{ml}^{-1}$ ketoconazole had fewer fungal contamination and gave higher number of actinomycete colonies (data not shown). Therefore, these two media were then applied for all soil samples. After incubating the plates at $28{ }^{\circ} \mathrm{C}$ for 28 days, colonies of actinomycetes were counted. Most soil samples showed actinomycete colonies $<30 \mathrm{CFU}$ per plate on Gause no. 1 medium, which had been spread with soil suspension at a dilution of 1:4. The highest number of actinomycete colonies $\left(2.48 \times 10^{4} \mathrm{CFUg}^{-1}\right.$ soil $)$ was found in rice plant rhizospheric soil sample (R2) on SCA medium (Table 1). In total, 351 actinomycete isolates were obtained from 21 soil samples (276 isolates from rice rhizospheres and 75 isolates from rubber tree rhizospheres). The highest number of actinomycete isolates $(n=28)$ were obtained from sample R11, and the lowest number of only one isolate from sample R12.

\section{Characterization of the isolates}

The detection result of 2,6-DAP from whole-cell hydrolysates showed that 325 isolates $(93.2 \%)$ contained $L L$-DAP. From their morphological characteristics and the DAP type, this majority of isolates were then assigned to the streptomycete group. This number included members of the genus Streptacidiphilus, which has similar colony morphology and DAP type as the genus Streptomyces. These 325 isolates were classified into five color groups based on their spore color on ISP medium 3. The isolates which produced gray spore color were dominant $(53.5 \%)$, followed by brown $(18.5 \%)$, white $(4.9 \%)$, yellow $(4.6 \%)$ and green $(1.5 \%)$. Fifty-five isolates $(16.9 \%)$ in the streptomycete group did not produce spores on acidified ISP medium 3 ( $\mathrm{pH}$ 5.5). The remaining 26 isolates (6.8\%), containing meso-DAP, were assigned to the non-streptomycete or rare actinomycete group. Representatives of these non-streptomycetes (23 isolates) and streptomycetes ( 35 isolates) were identified to the genus level by $16 \mathrm{~S}$ rRNA gene sequences analysis.

All 351 isolates were evaluated for their $\mathrm{pH}$ requirement for growth. The results showed that 212 isolates could grow better on $\mathrm{pH} 4.5$ medium when compared with $\mathrm{pH} 7.5$ and were assigned to acidophilic actinomycetes. However, they were not strictly acidophilic actinomycetes because these isolates could grow on medium $\mathrm{pH}$ 7.5. Ninety isolates grew better on $\mathrm{pH} 7.5$ medium when compared with $\mathrm{pH} 4.5$ and the remaining 49 isolates which grew only on $\mathrm{pH} 7.5$ medium were assigned to neutrophilic actinomycetes. A previous study reported that acidophilic actinomycetes were present in soils in which the $\mathrm{pH}$ did not exceed 6.8 and were not found in slightly alkaline soil. ${ }^{44}$ However, in this study acidophilic actinomycetes were found in all soil samples including those with slightly alkaline $\mathrm{pH}$. One possible explanation is that soils are heterogeneous systems with multiple microzones, where $\mathrm{pH}$ may considerably differ from the average value. In acidic soil, neutrophilic actinomycetes grew and generated spores in microsites of ammonia adsorption on organic fragments and the spores survived. ${ }^{8}$ On the other hand, acidophilic actinomycetes could grow in alkaline soils around plant roots that release $\mathrm{H}^{+}$for nutrient exchange, causing acid microsite, and they were recovered on an acidified isolation media.

Among 325 streptomycete isolates, 205 isolates were classified to acidophilic strains and 120 isolates to neutrophilic strains. Nineteen isolates of non-streptomycetes were classified to neutrophilic strains,

Table 2 Percentage of acidophilic and neutrophilic actinomycete antagonist against $\boldsymbol{F}$. moniliforme, $\boldsymbol{H}$. oryzae and $\boldsymbol{R}$. solani based on inhibition level of fungal growth

Percentage of actinomycetes antagonist against pathogenic fungi

\begin{tabular}{|c|c|c|c|c|c|c|}
\hline \multirow[b]{2}{*}{ Inhibition level } & \multicolumn{2}{|c|}{ F. moniliforme } & \multicolumn{2}{|c|}{ H. oryzae } & \multicolumn{2}{|c|}{ R. solani } \\
\hline & Acidophiles & Neutrophiles & Acidophiles & Neutrophiles & Acidophiles & Neutrophiles \\
\hline- & 33.96 & 54.68 & 61.79 & 76.26 & 31.60 & 76.98 \\
\hline+ & 7.55 & 15.11 & 15.57 & 9.35 & 4.72 & 0.00 \\
\hline++ & 35.85 & 22.30 & 11.79 & 9.35 & 20.75 & 10.79 \\
\hline+++ & 18.40 & 6.47 & 8.02 & 3.60 & 28.30 & 9.35 \\
\hline++++ & 4.25 & 1.44 & 2.83 & 1.44 & 14.62 & 2.88 \\
\hline Total & 100.00 & 100.00 & 100.00 & 100.00 & 100.00 & 100.00 \\
\hline
\end{tabular}

Ratings: - , No inhibition;,$+ \%$ inhibition $\geqslant 30 ;++, \%$ inhibition $\geqslant 50 ;+++, \%$ inhibition $\geqslant 70 ;++++, \%$ inhibition $>90$. 
whereas the other seven isolates were acidophilic strains. According to previous studies, streptomycetes were the most notable acidophilic actinomycetes, which is probably related to the fact that they are predominant in most soils. ${ }^{10,43,45}$

\section{Antifungal activity}

The in vitro antifungal activity assay showed that, 203 isolates (57.8\%), 114 isolates (32.5\%) and 177 isolates (50.4\%) suppressed F. moniliforme, H. oryzae and R. solani, respectively. Two hundred and thirty-nine isolates $(68.1 \%)$ inhibited at least one tested pathogenic fungus and 91 isolates (25.9\%) exhibited antifungal activity against all tested fungi. All antagonistic isolates belong to the streptomycete group except R8-39 and R13-3, which were non-streptomycete strains. Isolate R8-39 inhibited the growth of all tested fungi and R13-3 inhibited only F. moniliforme. The percentage of inhibition activity of isolate R8-39 to inhibit F. moniliforme, $H$. oryzae and $R$. solani were $74 \%, 84 \%$ and $71 \%$, respectively.

Nine streptomycete isolates exhibited $>80$ percent of inhibition against all pathogenic fungi. Among these, eight strains (R9-4, R14-1, R14-5, R14-6, R14-10, R18-16, R20-5 and R21-2) were acidophiles and only one strain (R19-3) was neutrophile. Strains R9-4, R14-1, R14-5 and R20-5, which gave the highest antagonistic activity, were selected for $16 \mathrm{~S}$ rRNA gene analysis.

Previous studies using actinomycetes isolated from neutral $\mathrm{pH}$ isolation media, reported lower percentages of antagonistic behavior toward F. moniliforme than that found in this study. Baniya and Vaidya $^{46}$ isolated 28 actinomycetes from vemicompost, of which only 4 isolates $(10.5 \%)$ were active against F. moniliforme. Hatamy et al. ${ }^{47}$ studied the inhibition activity of 100 actinomycetes isolated from greenhouse soil in Iran, reported that 18 strains showed high activity against F. moniliforme, and other neutrophilic actinomycetes showed antagonistic activity against $H$. oryzae and $R$. solani. Kathiresan et al. ${ }^{48}$ isolated 160 actinomycetes from sediment samples in India and found that about $51 \%$ and $31 \%$ of isolates were effective against $H$. oryzae and $R$. solani, respectively.

Acidophilic actinomycetes are usually scattered in acid terrestrial systems, ${ }^{45,49}$ in which they were important saprophytes and antagonistic microorganisms. ${ }^{21,30}$ It is important to explore actinomycetes having antifungal activity in acidic condition for direct use as biocontrol in acidic environment. Therefore, both acidophilic and neutrophilic actinomycetes were evaluated for their antifungal activity on acidic medium. Comparison of antifungal activity between acidophilic and neutrophilic actinomycetes (Table 2) showed that acidophilic isolates gave higher percentage of inhibition with all tested pathogenic fungi. In this experiment, all actinomycetes were evaluated for their antifungal activity on acidified agar, $\mathrm{pH}$ 5.5, and a greater proportion of acidophilic actinomycete isolates showed antifungal activity compared with neutrophilic strains under acidic condition. This may be due to the acidic condition that supported the growth of acidophilic more than neutrophilic isolates.

\section{Siderophore production}

Streptomycete isolated from roots of a Thai jasmine rice plant with siderophore production was reported to promote plant growth. ${ }^{50}$ In this experiment, the ability of all 351 isolates to produce siderophore was tested. Three hundred and thirty-eight isolates exhibited yellow to orange halos on chrome azurol S agar plate, and were thus considered to be siderophore producers. Two hundred and forty-five isolates $(69.8 \%)$ exhibited positive zone diameters in the range of $1.1-2.0 \mathrm{~cm}$, and 13 isolates exhibited zone diameters $>3.0 \mathrm{~cm}$. There were reports suggesting that the siderophore-producing bacteria could inhibit

Table 3 Identification of non-streptomycete isolates based on partial sequence of the 16S rRNA gene with their closest type strain from the EzTaxon-e database

\begin{tabular}{|c|c|c|c|c|c|}
\hline Genus & Strains & pH group & Accession no. & Closest type strains (Accession no.) & Similarity (\%) \\
\hline Allokutzneria & R8-39 & Neutrophile & AB841026 & A. albata DSM 44149 (AJ512462) & 98.8 \\
\hline \multirow[t]{5}{*}{ Amycolatopsis } & R8-21 & Acidophile & AB841020 & A. dongchuanensis YIM 75904 (JN656710) & 98.7 \\
\hline & $\mathrm{R} 13-25$ & Acidophile & AB841035 & A. dongchuanensis YIM 75904' (JN656710) & 98.7 \\
\hline & R13-26 & Acidophile & AB841036 & A. dongchuanensis YIM 75904' (JN656710) & 98.7 \\
\hline & $\mathrm{R} 12-7$ & Acidophile & AB841033 & A. tolypomycina DSM $44544^{\top}$ (AJ508241) & 99.2 \\
\hline & R15-35 & Acidophile & AB841044 & A. dongchuanensis YIM 75904 (JN656710) & 98.3 \\
\hline \multirow[t]{4}{*}{ Mycobacterium } & $\mathrm{R} 13-27$ & Neutrophile & AB841037 & M. poriferae ATCC 35087 (AF480589) & 99.0 \\
\hline & $\mathrm{R} 13-28$ & Neutrophile & AB841038 & M. poriferae ATCC $35087^{\top}$ (AF480589) & 98.8 \\
\hline & R13-29 & Neutrophile & AB841039 & M. poriferae ATCC $35087^{\top}$ (AF480589) & 98.5 \\
\hline & R13-30 & Neutrophile & AB841040 & M. poriferae ATCC $35087^{\top}$ (AF480589) & 98.9 \\
\hline \multirow[t]{2}{*}{ Nocardia } & R5-25 & Neutrophile & AB841007 & N. elegans IMMIB N-402 (AJ854057) & 99.9 \\
\hline & R5-26 & Neutrophile & AB841008 & N. elegans IMMIB N-402 (AJ854057) & 99.9 \\
\hline \multirow[t]{9}{*}{ Nonomuraea } & $\mathrm{R} 2-45$ & Neutrophile & AB841002 & N. wenchangensis $210417^{\top}$ (FJ261959) & 99.4 \\
\hline & R8-35 & Neutrophile & AB841023 & N. wenchangensis $210417^{\top}$ (FJ261959) & 99.7 \\
\hline & R8-36 & Neutrophile & AB841024 & N. wenchangensis $210417^{\top}$ (FJ261959) & 99.7 \\
\hline & R5-34 & Neutrophile & AB841009 & N. jabiensis A4036' (HQ157186) & 99.3 \\
\hline & R6-19 & Neutrophile & AB841014 & N. endophytica YIM 65601' (GU367158) & 99.9 \\
\hline & R6-20 & Neutrophile & AB841015 & N. candida $\mathrm{HMC}^{\top} 0^{\top}$ (DQ285422) & 98.8 \\
\hline & R5-35 & Neutrophile & AB841010 & N. pusilla IFO 14684 (U48978) & 99.8 \\
\hline & R5-37 & Neutrophile & AB841012 & N. pusilla IFO $14684^{\top}$ (U48978) & 99.7 \\
\hline & R5-36 & Neutrophile & AB841011 & N. candida $\mathrm{HMC}^{\top} \mathrm{T}^{\top}$ (DQ285421) & 99.2 \\
\hline Saccharopolyspora & R7-2 & Neutrophile & AB841016 & S. shandongensis $88^{\top}$ (EF104116) & 99.2 \\
\hline Verrucosispora & $\mathrm{R} 8-37$ & Neutrophile & AB841025 & V. maris AB-18-032' (AY528866) & 99.2 \\
\hline
\end{tabular}

Abbreviation: rRNA, ribosomal RNA. 
fungi by Fe ion uptake competition. The produced siderophore could inhibit the growth of fungi or induce the resistance of the plant to phytopathogenic fungi. ${ }^{51-53}$ Rhizospheric soil actinomycetes were also reported to inhibit the growth of phytopathogens and produce siderophore. ${ }^{54}$ In this study, $70.4 \%$ of siderophore-producing strains exhibited antifungal activities. On the other hand, 12 of 13 strains shown no siderophore production and could not inhibit any pathogenic fungi (F. moniliforme, H. oryzae and R. solani).

The comparison of acidophilic and neutrophilic actinomycetes for siderophore production showed that the percentage of siderophore-producing acidophilic strains was slightly higher than neutrophilies. The proportion of siderophore production by

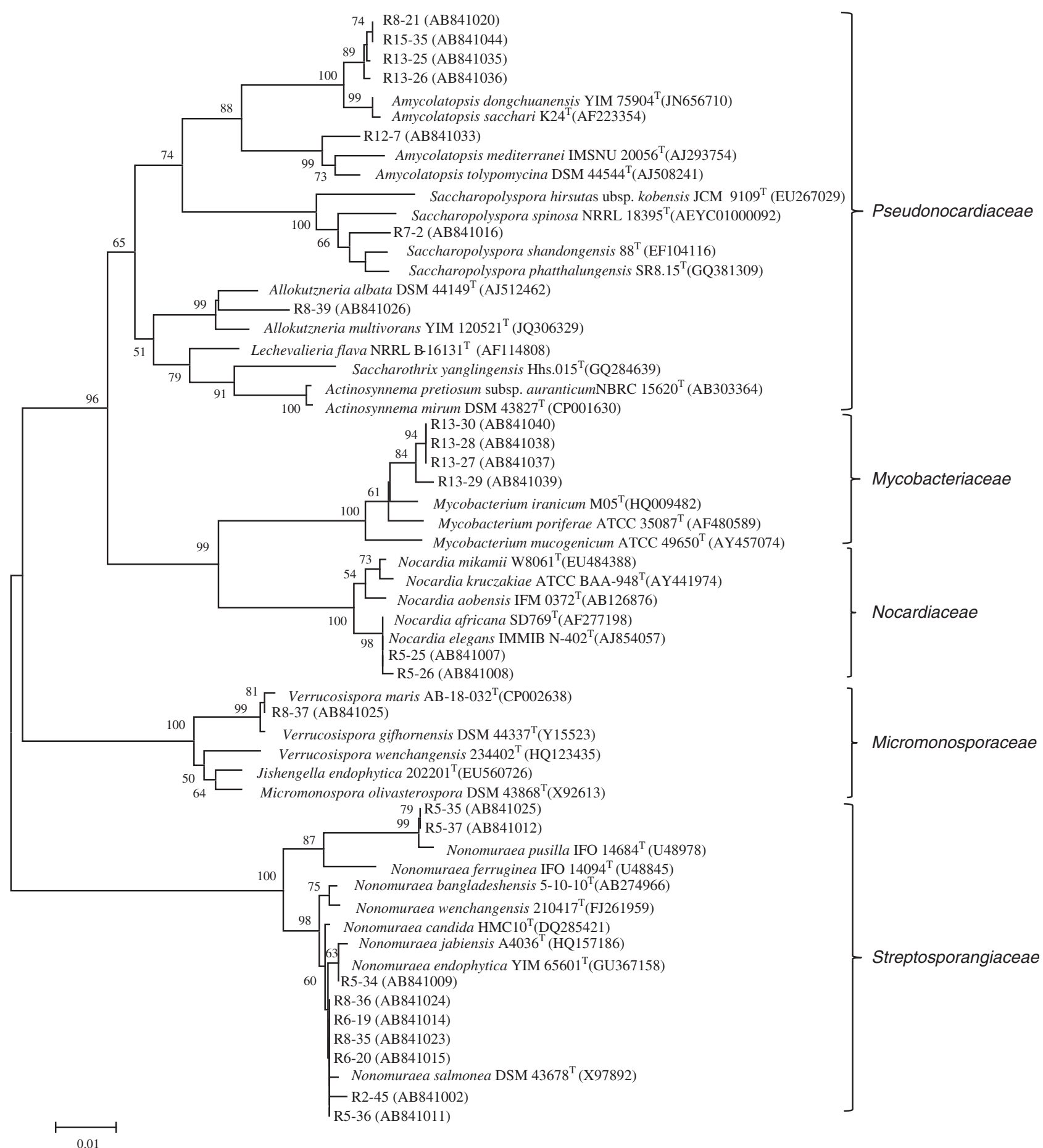

Figure 1 Neighbor-joining tree based on 851 aligned positions within the 16S rRNA gene, omitting regions of ambiguous alignment, showing relationships between the non-streptomycete isolates and related type strains. Numbers at the nodes indicate bootstrap values based on 1000 replicates; only values $>50 \%$ are given. The scale bar indicates 0.01 substitutions per nucleotide position. 
Table 4 Identification of representative streptomycete isolates based on the sequence of the 16S rRNA gene with their closest type strain from the EzTaxon-e database

\begin{tabular}{|c|c|c|c|c|}
\hline Isolates & $\mathrm{pH}$ group & Accession no. & Closest type strains (accession no.) & Similarity (\%) \\
\hline R1-17 & Acidophile & AB840998 & S. misionensis NBRC $13063^{\top}$ (AB184285) & 99.6 \\
\hline R2-26 & Acidophile & AB840999 & S. shenzhenensis $172115^{\top}$ (HQ660226) & 99.9 \\
\hline R2-36 & Neutrophile & AB841000 & S. niveiscabiei S78 ${ }^{\top}$ (AF361786) & 98.0 \\
\hline R2-38 & Neutrophile & AB841001 & S. filipinensis NBRC $12860^{\top}$ (AB184198) & 98.8 \\
\hline R3-2 & Acidophile & AB841003 & S. misionensis NBRC $13063^{\top}$ (AB184285) & 99.6 \\
\hline $\mathrm{R} 4-2$ & Acidophile & AB841004 & S. misionensis NBRC $13063^{\top}$ (AB184285) & 99.6 \\
\hline R5-13 & Acidophile & AB841005 & S. misionensis NBRC $13063^{\top}$ (AB184285) & 99.6 \\
\hline R5-21 & Acidophile & AB841006 & S. griseorubens NBRC $12780^{\top}$ (AB184139) & 100 \\
\hline R6-2 & Neutrophile & AB841013 & S. griseorubens NBRC $12780^{\top}$ (AB184139) & 100 \\
\hline R7-6 & Neutrophile & AB841017 & S. albogriseolus NRRL B-1305 (AJ494865) & 100 \\
\hline R7-28 & Acidophile & AB841018 & S. corchorusii NBRC $13032^{\top}$ (AB184267) & 100 \\
\hline R8-11 & Neutrophile & AB841019 & S. coeruleorubidus NBRC $12844^{\top}$ (AB184849) & 99.6 \\
\hline R8-29 & Neutrophile & AB841021 & S. parvulus NBRC $13193^{\top}$ (AB184326) & 100 \\
\hline R8-31 & Neutrophile & AB841022 & S. geysiriensis NBRC $15413^{\top}$ (AB184661) & 99.5 \\
\hline R9-4 & Acidophile & AB841027 & S. misionensis NBRC $13063^{\top}$ (AB184285) & 99.8 \\
\hline R9-5 & Acidophile & AB841028 & S. corchorusii NBRC $13032^{\top}$ (AB184267) & 100 \\
\hline R9-20 & Acidophile & AB841029 & S. corchorusii NBRC $13032^{\top}$ (AB184267) & 100 \\
\hline R11-2 & Neutrophile & AB841030 & S. coeruleorubidus NBRC $12844^{\top}$ (AB184849) & 99.4 \\
\hline R11-21 & Acidophile & AB841031 & S. viridobrunneus LMG 20317 (AJ781372) & 99.6 \\
\hline R11-28 & Neutrophile & AB841032 & S. carpinensis NBRC $14214^{\top}$ (AB184574) & 99.4 \\
\hline R13-24 & Neutrophile & AB841034 & S. albogriseolus NRRL B-1305 (AJ494865) & 99.8 \\
\hline R14-1 & Acidophile & AB841041 & S. misionensis NBRC $13063^{\top}$ (AB184285 & 99.8 \\
\hline R14-5 & Acidophile & AB841042 & S. misionensis NBRC $13063^{\top}$ (AB184285) & 99.7 \\
\hline R14-7 & Neutrophile & AB841043 & S. graminearus LMG 19904 (AJ781333) & 98.6 \\
\hline R16-4 & Acidophile & AB841045 & S. shenzhenensis $172115^{\top}$ (HQ660226) & 99.3 \\
\hline R16-29 & Neutrophile & AB841046 & S. rubrogriseus LMG 20318 (AJ781373) & 99.8 \\
\hline R16-30 & Acidophile & AB841047 & S. misionensis NBRC $13063^{\top}$ (AB184285) & 99.5 \\
\hline R16-35 & Acidophile & AB841048 & S. chromofuscus NBRC $12851^{\top}$ (AB184194) & 99.3 \\
\hline R16-37 & Acidophile & AB841049 & S. misionensis NBRC $13063^{\top}$ (AB184285) & 99.6 \\
\hline $\mathrm{R} 18-16$ & Acidophile & AB841050 & S. olivaceoviridis NBRC $13066^{\top}$ (AB184288) & 100 \\
\hline $\mathrm{R} 18-18$ & Acidophile & AB841051 & S. spiralis NBRC $14215^{\top}$ (AB 184575) & 99.9 \\
\hline R18-25 & Acidophile & AB841052 & S. capoamus JCM 4734 (AB045877) & 100 \\
\hline R18-31 & Acidophile & AB841053 & S. thermoviolaceus DSM 41392 (Z68095) & 99.2 \\
\hline R19-5 & Acidophile & AB841054 & S. misionensis NBRC $13063^{\top}$ (AB184285) & 99.9 \\
\hline R19-6 & Acidophile & AB841055 & S. misionensis NBRC $13063^{\top}$ (AB184285) & 99.9 \\
\hline R20-1 & Acidophile & AB841056 & S. misionensis NBRC $13063^{\top}$ (AB184285) & 100 \\
\hline R20-5 & Acidophile & AB841057 & S. misionensis NBRC $13063^{\top}$ (AB184285) & 99.7 \\
\hline R21-27 & Neutrophile & AB841058 & S. chiangmaiensis TA4-1 ${ }^{\top}$ (AB562507) & 99.2 \\
\hline R21-45 & Acidophile & AB841059 & S. althioticus NRRL B-3981 (AY999791) & 99.7 \\
\hline
\end{tabular}

acidophilic strains was $98.6 \%$ compared with $92.8 \%$ in neutrophiles.

\section{Phosphate solubilization}

Among 351 actinomycetes, 266 isolates (75.8\%) showed an ability to solubilize phosphate on Pikovskaya agar with the diameters of clear zones ranging from $0.7-1.6 \mathrm{~cm}$. Only six isolates produced clear zones with diameters $>1.5 \mathrm{~cm}$. Five isolates were acidophiles and one isolate was neutrophile.

Phosphorus is an important element for plant growth. However, most of the phosphorus in soil are in insoluble forms, which are unavailable for plants. Deficiency of phosphate has negative effect on agricultural yield. Actinomycetes were reported to possess the ability to solubilize phosphate and thus significantly promote the growth of plants. ${ }^{55,56}$ In acidic soils, phosphorus limitation is a serious problem because phosphorus forms complexes with metal ions. ${ }^{57}$ In this experiment, it was found that $93.9 \%$ of the acidophilic group and
$48.2 \%$ of the neutrophilic group were able to solubilize phosphate. This indicated that phosphate-solubilizing acidophilic actinomycetes might have an important role in the phosphorus cycle in acidic soils.

\section{S rRNA gene analysis}

The 16S rRNA gene sequencing analysis was carried out on 23 nonstreptomycete isolates, which were preliminary identified on the basis of morphological characteristics and chemotaxonomic analysis. The resultant sequences were determined and compared with the sequences available in the EzTaxon-e database. The percentages of $16 \mathrm{~S}$ rRNA gene sequence identity of these isolates to the closest type strain are presented in Table 3. The results revealed that they were members of the following genera: Allokutzneria (one isolate, family Pseudonocardiaceae), Amycolatopsis (five isolates, family Pseudonocardiaceae), Nocardia (two isolates, family Nocardiaceae), Nonomuraea (nine isolates, family Streptosporangiaceae), Mycobacterium (four isolates, family Mycobacteriaceae), Saccharopolyspora (one isolate, 


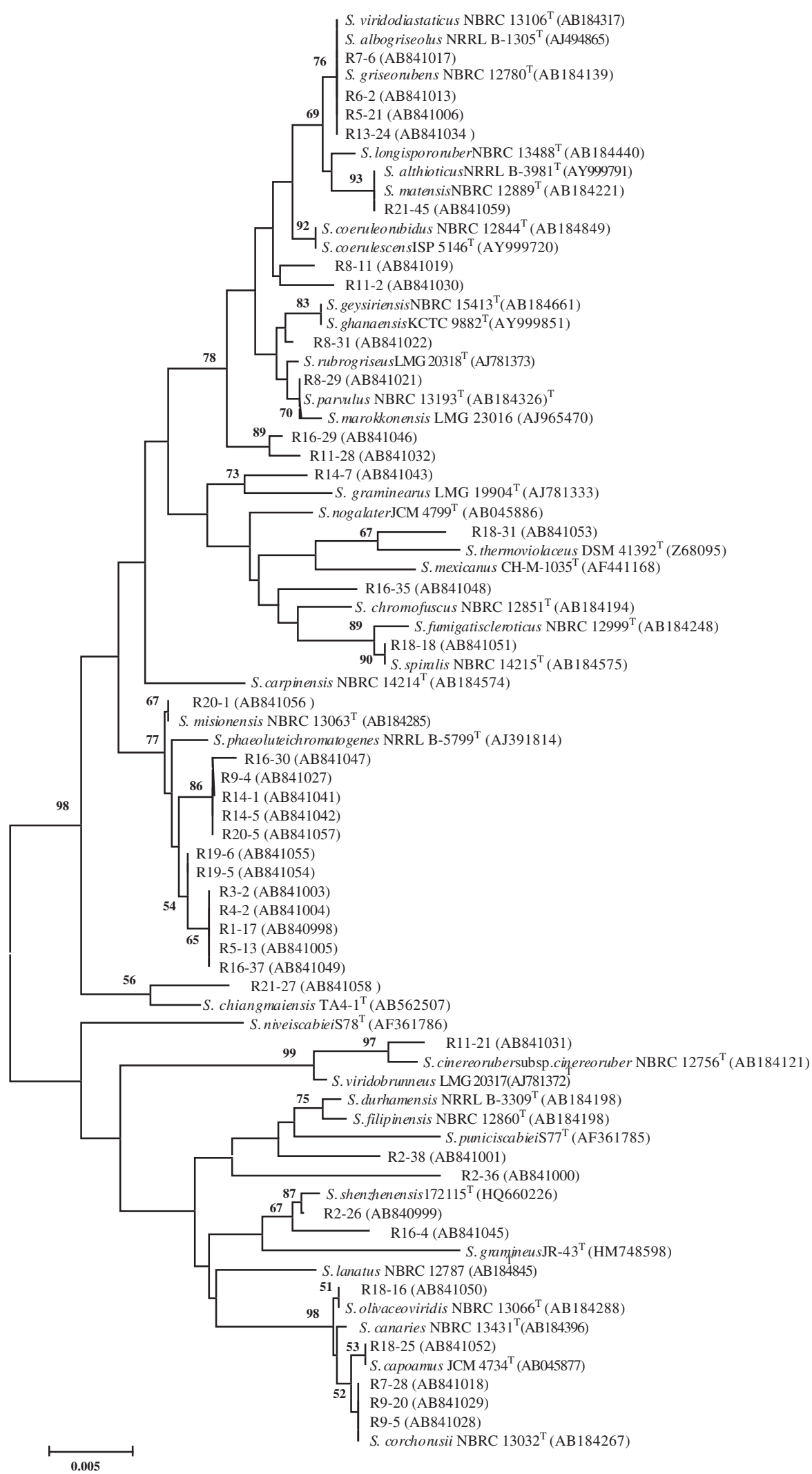

Figure 2 Neighbor-joining tree based on 1422 aligned positions within the 16S rRNA gene, omitting regions of ambiguous alignment, showing relationships between the Streptomyces isolates and related Streptomyces type strains. Numbers at the nodes indicate bootstrap values based on 1000 replicates; only values $>50 \%$ are given. The scale bar indicates 0.005 substitutions per nucleotide position. 
family Pseudonocardiaceae) and Verrucosispora (one isolate, family Micromonosporaceae). The genus Nonomuraea was the most frequently found. Most of non-streptomycete isolates were neutrophiles; the five exceptions were members of the genus Amycolatopsis (isolates R8-21, R12-7, R13-25, R13-26 and R15-35), which were acidophiles. Phylogenetic tree constructed based on the 16S rRNA gene sequences, which was supported by high bootstrap values, confirmed their affiliation to these families is shown in Figure 1. Based on colonial characteristics and morphological characteristics under light microscope, another non-streptomycete isolate R13-3, which showed ability to inhibit F. moniliforme was presumed a member of isolates R8-21, R13-25, R13-26 and R15-35, which identified to the genus Amycolatopsis by $16 \mathrm{~S}$ rRNA gene sequence analysis.

In this study, one strain of the genus Allokutzneria (strain R8-39) was isolated from a rice rhizosphere soil. The genus Allokutzneria encompasses only two species, Allokutzneria albata and Allokutzneria multivorans, which were isolated from soils in the Philippines and China, respectively. ${ }^{58-60}$ Only $A$. albata has been reported to produce a highly active antiviral antibiotic (cycloviracin). ${ }^{58}$ The strain R8-39 shared the highest $16 \mathrm{~S}$ rRNA gene similarity of $98.8 \%$ to A. albata and clustered with A. albata and A. multivorans in the $16 \mathrm{~S}$ rRNA gene tree, which formed a well separated clade supported by a $99 \%$ bootstrap value in the family Pseudonocardiaceae (Figure 1). This observation suggests that the strain R8-39 may represent a new species in the genus Allokutzneria. However, detailed polyphasic taxonomic characterization of the strain is required to clarify its status.

Analysis of $16 \mathrm{~S}$ rRNA gene sequences of 35 representative $L L$-DAPcontaining isolates and 4 isolates, which showed the highest antifungal activity, could be confirmed and assigned to the genus Streptomyces. The isolates with high similarity to $S$. misionensis were frequently found in different soil samples (Table 4). Phylogenetic tree of the resulting $16 \mathrm{~S}$ rRNA gene sequences assigned them into clusters in the Streptomyces genus (Figure 2). The biggest cluster consisted of 13 acidophilic strains and the closest neighbor was S. misionensis, which had 16S rRNA sequence similarities of $99.5-100 \%$. The $16 \mathrm{~S}$ rRNA gene sequences of four effective antifungal isolates (R9-4, R141, R14-5 and R20-5) also fell into this cluster although these strains had been isolated from different soil samples. These four isolates produced whitish aerial mycelium, grayish spore and yellowish to grayish brown reversed color on acidified ISP medium 3 ( $\mathrm{pH} 5.5$ ). The isolates R9-4, R14-5 and R20-5 produced yellow diffusible pigment which was not detected in R14-1. Melanoid pigment was not produced on ISP medium 7. Microscopic observation revealed the formation of compact spiral chain of spores.

Acidic environments are major selective pressures of members of the genus Streptacidiphilus. ${ }^{49}$ A previous work using soil samples collected from rice field soil from Thailand reported the isolation of Streptacidiphilus oryzae JCM $13271^{\mathrm{T}}{ }^{61}$ However, no member of the genus Streptacidiphilus was recovered in this study. This may be due to the fact that the $\mathrm{pH}$ of the isolation media not being acidified to the optimum $\mathrm{pH}$ for members of the Streptacidiphilus.

S. misionensis strains have been previously reported to exhibit antimicrobial activity such as S. misionensis strain NRRL 3609, which produced substance that could inhibit growth of various fungi including Candida albicans and Cryptococcus neoformans. ${ }^{62}$ $S$. misionensis strain PMS101 isolated from the rhizosphere of healthy lily bulbs was reported to have antagonistic activity, reducing the incidence of seedling blight caused by Fusarium proliferatum and effectively control basal rot caused by Fusarium oxysporum f. sp. lilii. ${ }^{63}$ There is no report on pathogenicity of S. misionensis to human, animals or plants. This suggests that $S$. misionensis strains could be used as safe biocontrol agents. In rice field soil, the $\mathrm{pH}$ is usually slightly acidic. S. misionensis strains R9-4, R14-1, R14-5 and R20-5 were neurotolerant acidophiles that exhibited efficient antagonistic activity against rice pathogenic fungi (F. moniliforme, $H$. oryzae and $R$. solani). In addition, all except R9-4 produced siderophore, and all of them solubilized phosphate. As a result, S. misionensis strains R9-4, R14-1, R14-5 and R20-5 are potential candidates for use in a sustainable development of agriculture especially in acidic paddy soil. The evaluation of active metabolites, produced by actinomycetes in acidic conditions, indicates the importance to isolate certain groups of species that have useful biological activities under such condition and may not be usually recovered by standard isolation procedures.

\section{ACKNOWLEDGEMENTS}

This research was supported by the scholarship to promote international publication from the Graduate School Kasetsart University to NP. This work was also supported by the Higher Education Research Promotion and the National Research University Project of Thailand, Office of the Higher Education Commission.

1 Sanglier, J. J., Haag, H., Huck, T. \& Fehr, T. Section review; anti-infectives: review of actinomycetes compounds 1990-1995. Expert Opin. Investig. Drugs 5, 207-223 (1996).

2 Lazzarini, A., Cavaletti, L., Toppo, G. \& Marinelli, F. Rare genera of actinomycetes as potential producers of new antibiotics. Antonie van Leeuwenhoek 78, 399-405 (2000).

3 Procópio, R. E., Silva, I. S., Martins, M. K., Azevedo, J. L. \& Araújo, J. M. Antibiotics produced by Streptomyces. Braz. J. Infect. Dis. 16, 466-471 (2012).

4 Jensen, H. L. Actinomyces acidophilus n. sp. A group of acidophilus actinomycetes isolated from the soil. Soil Sci. 25, 225-236 (1928).

$5 \mathrm{Kim}$, S., Lonsdale, J., Seong, C. \& Goodfellow, M. Streptacidiphilus gen. nov., acidophilic actinomycetes with wall chemotype I and emendation of the family Streptomycetaceae (Waksman and Henrici (1943) $)^{\mathrm{AL}}$ ) emend. Rainey et al. 1997. Antonie van Leeuwenhoek 83, 107-116 (2003).

6 Cavaletti, L. et al. Actinospica robiniae gen. nov. and Actinospica acidiphila sp. nov.: proposal for Actinospicaceae fam. nov. and Catenulisporineae subord. nov. in the order Actinomycetales. Int. J. Syst. Evol. Microbiol. 56, 1747-1753 (2006).

7 Busti, E. et al. Catenulispora acidiphila gen. nov., sp. nov., a novel, mycelium-forming actinomycete, and proposal of Catenulisporaceae fam. nov. Int. J. Syst. Evol. Microbiol. 56, 1741-1746 (2006).

8 Williams, S. T. \& Mayfield, C. I. Studies on the ecology of actinomycetes in soil III: the behaviour of neutrophilic streptomycetes in acid soil. Soil Biol. Biochem. 3, 197-208 (1971).

9 Xu, C. et al. Neutrotolerant acidophilic Streptomyces species isolated from acidic soils in China: Streptomyces guanduensis sp. nov., Streptomyces paucisporeus sp. nov., Streptomyces rubidus sp. nov. and Streptomyces yanglinensis sp. nov. Int. J. Syst. Evol. Microbiol. 56, 1109-1115 (2006).

10 Zenova, G. M., Manucharova, N. A. \& Zvyagintsev, D. G. Extremophilic and extremotolerant actinomycetes in different soil types. Eurasian Soil Sci. 44, 417-436 (2011).

$11 \mathrm{Ou}, \mathrm{S} . \mathrm{H}$. Rice Diseases. 2nd edn (CAB International, Slough, England, 1987).

12 Tsukano, Y. Transformations of selected pesticides in flooded rice-field soil. J. Contam. Hydrol. 1, 47-63 (1986).

13 Pingali, P. L., Marquez, C. B., Palis, F. G. \& Rola, A. C. in Impact of Pesticides on Farmer Health and the Rice Environment. The Impact of Pesticides on Farmer Health: A Medical and Economic Analysis in the Philippines (eds Pingali, P. L. \& Roger, P. A.) 343-360 (Kluwer Academic Publishers, Massachusetts, USA, 1995).

14 Basilio, R. et al. Patterns of antimicrobial activities from soil actinomycetes isolated under different conditions of $\mathrm{pH}$ and salinity. J. Appl. Microbiol. 95, 814-823 (2003)

$15 \mathrm{Li}, \mathrm{Q}$. et al. Suppression of Magnaporthe oryzae by culture filtrates of Streptomyces globisporus JK-1. Biol. Control 58, 139-148 (2011).

16 Patil, H. J., Srivastava, A. K., Singh, D. P., Chaudhari, B. L. \& Arora, D. K. Actinomycetes mediated biochemical responses in tomato (Solanum lycopersicum) enhances bioprotection against Rhizoctonia solani. Crop Prot. 30, 1269-1273 (2011).

17 Yuan, W. M. \& Crawford, D. L. Characterization of Streptomyces lydicus WYEC108 as a potential biocontrol agent against fungal root and seed rots. Appl. Environ. Microbiol. 61, 3119-3128 (1995).

18 Gomes, R. C. et al. Chitinolytic activity of actinomycetes from a cerrado soil and their potential in biocontrol. Lett. Appl. Microbiol. 30, 146-150 (2000).

19 El-Tarabily, K. A. \& Sivasithamparam, K. Non-streptomycete actinomycetes as biocontrol agents of soil-borne fungal plant pathogens and as plant growth promoters. Soil Biol. Biochem. 38, 1505-1520 (2006). 
$20 \mathrm{Xue}$, L. et al. Isolation and evaluation of rhizosphere actinomycetes with potentia application for biocontrol of Verticillium wilt of cotton. Crop Prot. 43, 231-240 (2013).

21 Zakalyukina, Y. V. \& Zenova, G. M. Antagonistic activity of soil acidophilic actinomycetes. Biol. Bull. Russ. Acad. Sci. 34, 329-332 (2007).

22 Crawford, D. L., Lynch, J. M., Whipps, J. M. \& Ousley, M. A. Isolation and characterization of actinomycete antagonists of a fungal root pathogen. Appl. Environ. Microbiol. 59, 3899-3905 (1993).

23 Davet, P. Microbial Ecology of Soil and Plant Growth (Science Publisher, New Hampshire, USA, 2004).

24 Küster, E. \& Williams, S. T. Selection of media for isolation of streptomycetes. Nature 202, 928-929 (1964).

25 Gauze, G. F. et al. Problems in the Classification of Antagonistic Actinomycetes (State Publishing House for Medical Literature, Moscow, Russia, 1957).

26 Shirling, E. B. \& Gottlieb, D. Methods for characterization of Streptomyces species. Int. J. Syst. Bacteriol. 16, 313-340 (1966).

27 Mundie, D. A. The NBS/ISCC Color System/David A. Mundie Pittsburgh, PA:24 Polymath Systems 535.6 dc-20. The NBS/ISCC Color System (1995), http://www.dodomagnifico.com/Colors/NBS.html. Accessed 5 June 2011

28 Hasegawa, T., Takizawa, M. \& Tanida, S. A rapid analysis for chemical grouping of aerobic actinomycetes. J. Gen. Appl. Microbiol. 29, 319-322 (1983).

29 Becker, B., Lechevalier, M. P., Gordon, R. E. \& Lechevalier, H. A. Rapid differentiation between Nocardia and Streptomyces by paper chromatography of whole-cell hydrolysates. Appl. Microbiol. 12, 421-423 (1964).

30 Khan, M. R. \& Williams, S. T. Studies on the ecology of actinomycetes in soil VIII: Distribution and characteristics of acidophilic actinomycetes. Soil Biol. Biochem. 7 , 345-348 (1975).

31 Rahman, M. A., Begum, M. F. \& Alam, M. F. Screening of Trichoderma isolates as a biological control agent against Ceratocystis paradoxa causing pineapple disease of sugarcane. Mycobiol 37, 277-285 (2009).

32 Panhwar, Q. A., Othman, R., Rahman, Z. A., Meon, S. \& Ismail, M. R. Isolation and characterization of phosphate-solubilizing bacteria from aerobic rice. Afr. J. Biotechnol. 11, 2711-2719 (2012)

33 Schwyn, B. \& Neilands, J. B. Universal chemical assay for the detection and determination of siderophores. Anal. Biochem. 160, 47-56 (1987).

34 Pikovskaya, R. I. Mobilization of phosphorus in soil in connection with vital activity of some microbial species. Microbiology 17, 362-370 (1948).

35 Kieser, T., Bibb, M. J., Buttner, M., Chater, K. F. \& Hopwood, D. A. Practical Streptomyces Genetics (The John Innes Foundation, Norwich, England, 2000).

36 Kataoka, M., Ueda, K., Kudo, T., Seki, T. \& Yoshida, T. Application of the variable region in 16S rDNA to create an index for rapid species identification in the genus Streptomyces. FEMS Microbiol. Lett. 151, 249-255 (1997).

37 Thompson, J. D., Higgins, D. G. \& Gibson, T. J. CLUSTAL W: improving the sensitivity of progressive multiple sequence alignment through sequence weighting, positionspecific gap penalties and weight matrix choice. Nucleic Acids Res. 22, 4673-4680 (1994).

38 Jukes, T. H. \& Cantor, C. R. in Mammalian Protein Metabolism. Evolution of Protein Molecules in Mammalian Protein Metabolism (ed Munro, H.) 21-132 (Academic Press, New York, USA, 1969).

39 Tamura, K. et al. MEGA5: molecular evolutionary genetics analysis using maximum likelihood, evolutionary distance, and maximum parsimony methods. Mol. Biol. Evol. 28, 2731-2739 (2011).

40 Kimura, M. A simple method for estimating evolutionary rate of base substitutions through comparative studies of nucleotide sequences. J. Mol. Evol. 16, 111-120 (1980).

41 Rantala, L. Rubber plantation performance in the Northeast and East of Thailand in relation to environmental conditions (Dissertation, University of Helsinki, 2006).

42 Yagi, K. \& Minami, K. Effect of organic matter application on methane emission from some Japanese paddy fields. Soil Sci. Plant Nutr. 36, 599-610 (1990).
43 Muramatsu, $\mathrm{H}$. et al. Phylogenetic diversity of acidophilic actinomycetes from Malaysia. J. Antibiot. 64, 621-624 (2011).

44 Zakalyukina, Y. V., Zenova, G. M. \& Zvyagintsev, D. G. Acidophilic soil actinomycetes. Microbiology 71, 342-345 (2002)

45 Hagedorn, C. Influences of soil acidity on Streptomyces populations inhabiting forest soils. Appl. Environ. Microbiol. 32, 368-375 (1976).

46 Baniya, R. \& Vaidya, G. S. Antifungal activity of actinomycetes from vermicompost and their morphological and biochemical characterization. Nepal J. Sci. Technol. 12, 97-102 (2011).

47 Hatamy, N., Bonjar, G. H. S. \& Sadeghy, B. Screening and isolation of actinomycetes isolates in biological control of Fusarium solani, F. moniliforme and F. subglutinans the causal agent of rot root of greenhouse cucumber in vitro conditions. Arch. Phytopathol. Plant Prot. 47, 437-441 (2014).

48 Kathiresan, K., Balagurunathan, R. \& Selvam, M. M. Fungicidal activity of marine actinomycetes against phytopathogenic fungi. Indian J. Biotechnol. 4, 271-276 (2005).

49 Cho, S. H., Han, J. H., Seong, C. N. \& Kim, S. B. Phylogenetic diversity of acidophilic sporoactinobacteria isolated from various soils. J. Microbiol. 44, 600-606 (2006).

50 Rungin, S. et al. Plant growth enhancing effects by a siderophore-producing endophytic streptomycete isolated from a Thai jasmine rice plant (Oryza sativa L. cv. KDML105). Antonie van Leeuwenhoek 102, 463-472 (2012).

51 Duijff, B. J., Meijer, J. W., Bakker, P. A. H. M. \& Schippers, B. Siderophore-mediated competition for iron and induced resistance in the suppression of fusarium wilt of carnation by fluorescent Pseudomonas spp. Neth. J. Plant Pathol. 99, 277-289 (1993).

52 Matthijs, S. et al. Thioquinolobactin, a Pseudomonas siderophore with antifungal and anti-Phythium activity. Environ. Microbiol. 9, 425-434 (2007).

53 Tortora, M. A., Díaz-Ricci, J. C. \& Pedraza, R. O. Azospillum brasilense siderophores with antifungal activity against Collectotrichum acutatum. Arch. Microbiol. 193, 275-286 (2011).

54 Khamna, S., Yokota, A. \& Lumyong, S. Actinomycetes isolated from medicinal plant rhizosphere soils: diversity and screening of antifungal compounds, indole-3-acetic acid and siderophore production. World J. Microbiol. Biotechnol. 25, 649-655 (2009).

55 Hamdali, H. et al. Screening for rock phosphate solubilizing actinomycetes from Moroccan phosphate mines. Appl. Soil Ecol. 38, 12-19 (2008).

56 Hamdali, H., Hafidi, M., Virolle, M. J. \& Ouhdouch, Y. Growth promotion and protection against damping-off of wheat by two rock phosphate solubilizing actinomycetes in a P-deficient soil under greenhouse conditions. Appl. Soil Ecol. 40, 510-517 (2008).

57 Brady, N. C. \& Weil, R. R. The Nature and Properties of Soils (Prentice Hall, New York, USA, 1999).

58 Tomita, K., Hoshino, Y. \& Miyaki, T. Kibdelosporangium albatum sp. nov., producer of the antiviral antibiotics cycloviracins. Int. J. Syst. Bacteriol. 43, 297-301 (1993).

59 Cao, Y. R., Chen, X., Jiang, Y., Wang, L. S. \& Jiang, C. L. Allokutzneria multivorans sp. nov., an actinomycete isolated from soil. Int. J. Syst. Evol. Microbiol. 63, 1741-1746 (2013).

60 Labeda, D. P. \& Kroppenstedt, R. M. Proposal for the new genus Allokutzneria gen. nov. within the suborder Pseudonocardineae and transfer of Kibdelosporangium albatum Tomita et al. 1993 as Allokutzneria albata comb. nov. Int. J. Syst. Evol. Microbiol 58, 1472-1475 (2008).

61 Wang, L., Huang, Y., Liu, Z., Goodfellow, M. \& Rodriguez, C. Streptacidiphilus oryzae sp. nov., an actinomycete isolated from rice-field soil in Thailand. Int. J. Syst. Evol. Microbiol. 56, 1257-1261 (2006).

62 Martin, J. H. E. J. \& Porter, J. N. Antifungal BH890, US3700769 (1972).

63 Chung, W. C., Wu, R. S., Hsu, C. P., Huang, H. C. \& Huang, J. W. Application of antagonistic rhizobacteria for control of Fusarium seedling blight and basal rot of lily. Australasian Plant Pathol. 40, 269-276 (2011). 